\title{
FREQUENCY OF STROKE IN HYPERTENSIVE PATIENTS
}

\author{
Dr. Ashok Kumar Lohano', Dr. Adnan Samie ${ }^{2}$, Dr. Noor Nabi Siayal ${ }^{3}$
}

1. FCPS

Assistant Professor of Medicine Peoples University of Medical \& Health Sciences

Shaheed Benazirabad Nawabshah

2. FCPS-II, Trainee, Medical Unit-III,

Peoples University of Medical \&

Health Sciences

Shaheed Benazirabad Nawabshah

3. FCPS-II, Trainee, Medical Unit-III,

Peoples University of Medical \&

Health Sciences

Shaheed Benazirabad Nawabshah

Correspondence Address: Dr. Ashok Kumar Lohano Postal Address: Falt\#1,

PAK Plaza Trunk Bazar Nawabshah. drashokfcps@yahoo.com

\begin{abstract}
Objective: To determine the frequency of intracerebral hemorrhage in hypertensive patients. Study design: Cross sectional study. Setting: This study was conducted at Medical department of Peoples Medical College \& Hospital Nawabshah, from 01-01-2012 to 31-12-2012. Material and methods: Admitted patient through emergency department with history of hypertension more than two years, meeting the inclusion criteria taken consent from attendant. Patient was referred for C.T scan brain presence of hyperdense area was considered as intracerebral hemorrhage. Inclusive criteria were age $>20$ years, either sex and patients with history of hypertension more than two year with any two or more sign and symptoms like sudden unconsciousness or with hemiplegia, hemiparesis, dysarthria. Aphasia, cranial nerve palsies. Exclusion criteria were age less than 20 years, normotensive patients with cerebral hemorrhage and patients with traumatic hemorrhage. Results: Among 281 patients that had stroke, there were 147 males and 134 females with a sex ratio males: female 1:1. Mean age of patients admitted with intracerebral hemorrhage was $37.89 \pm 7.33$ years with an average age among males and females was same. Duration of hypertension was greater than 20-25 years in most of the patients nearly $63.7 \%$. Patients with long duration of diabetes and hypertension presented with intracerebral hemorrhage. Nearly all the patients with intracerebral hemorrhage were smokers 145, only 2 patients were non smokers and nearly all had long history of smoking. The 127 patients who presented with intracerebral hemorrhage were obese. All risk factors were statistically significant and were responsible for intracerebral hemorrhage. Conclusions: Hypertension is a risk factor for intra cerebral hemorrhage. An effort should be made to control blood pressure and other modifiable risk factors to reduce incidence of intra cerebral hemorrhage and improve patient outcomes.
\end{abstract}

Key words: $\quad$ Intra cerebral hemorrhage, Hypertension, Diabetes.
Article Citation: Lohano AK, Samie A, Siayal NN. Frequency of stroke in hypertensive patients. Professional Med J 2014;21(3): 484-488.

\author{
Article received on: \\ 01/06/2013 \\ Accepted for Publication \\ $18 / 11 / 2013$ \\ Received after proof reading: \\ 27/05/2014
}

\section{INTRODUCTION}

Intracerebral hemorrhage are caused by rupture or leak of blood vessel within the brain parenchyma that extends into the ventricles, and in rare cases, the subarachnoid spaces, most of stroke are ischemic $(87 \%)^{1}$. Important causes of intracerebral hemorrhage include hypertension, amyloid angiopathy, aneurysms, vascular malformation, and hemorrhagic infarcts (both venous and arterial) ${ }^{2}$.

The most common modifiable risk factor of intracerebral hemorrhage is hypertension seen in
$78.0 \%$ at presentation ${ }^{3}$. Hypertension is the one of the cause of death and disability in adult, and the hospital admission due to intracerebral hemorrhage, which is increasing gradually worldwide in the past 10 years, and the mortality has not been decreased ${ }^{4}$. The risk of intracerebral hemorrhage is more in males than female ${ }^{5}$.

In Pakistan a study conducted on adult pushtoon community residing in Karachi shows prevalence of $4.8 \%$ of hemorrhagic stroke which was alike in men and women. ${ }^{6}$. And the incidence rate of intracerebral hemorrhage on CT scan brain is 10 to 
30 cases per 100000 persons in the western countries $^{7}$. The worldwide incidence of stroke has variation from nation to nation, suggesting the importance of genetic and environmental factors. According to $\mathrm{WHO}, 15$ million people suffering from stroke worldwide each year ${ }^{8}$.

Intracerebral hemorrhage has a high morbidity and mortality, in hospitalized patients worldwide, Diagnosis is mostly clinical but it was wrong in 10$15 \%$ of cases so the brain imaging is necessary for accurate diagnosis like CT scan brain MRI brain, which are helpful to rule out stroke mimics and clinical management ${ }^{9}$. Intracerebral hemorrhage and subarachnoid hemorrhage are managed by supportive therapy and prevention of the complication by controlling the blood pressure and intracranial pressure through medication and ventriculostomy ${ }^{10}$.

The rational of study is as that data is deficient on the topic although study is done without appropriate sample size so the prevalence of intracerebral hemorrhage is questionable therefore the present study is design to estimate the actual magnitude of intracerebral hemorrhage in hypertensive patients so strategy could be develop to screen hypertensive patients and compliance insured, so that the morbidity could be reduced and decrease the economical burden and disability.

\section{MATERIAL AND METHODS}

This study was conducted at Medical department of Peoples Medical College \& Hospital Nawabshah, from 01-01-2012 to 31-12-2012. Admitted patient through emergency department with history of hypertension more than two years, meeting the inclusion criteria taken consent from attendant. Patient was referred for C.T scan brain presence of hyperdense area was considered as intracerebral hemorrhage. Inclusive criteria were age $\geq 20$ years, either sex and patients with history of hypertension more than two year with any two or more sign and symptoms like sudden unconsciousness or with hemiplegia, hemiparesis, dysarthria. Aphasia, cranial nerve palsies. Exclusion criteria were age less than 20 years, normotensive patients with cerebral hemorrhage and patients with traumatic hemorrhage. The collected data was entered and analyzed by using Statistical Package for Social Sciences (SPSS) software, Version 17. Effect modifier like age, gander, durations of hypertension and D.M, smoking and obesity was control through stratification applying chi square test. $\mathrm{P}$ value < equal to 0.05 was taken as significant.

\section{RESULTS}

Among 281 patients that had stroke, there were 147 males and 134 females with a sex ratio males: female 1:1. Mean age of patients admitted with intracerebral hemorrhage was $37.89 \pm 7.33$ years with an average age among males and females was same. Of 281 hypertensive patients $147(52.3 \%)$ patients presented with intracerebral hemorrhage, while the rest 128 (45.5\%) presented with ischemic stroke and 6 patients $(2.2 \%)$ had subarachnoid hemorrhage. Of 281 hypertensives there were 158(56.2\%) diabetics, 154 (54.8\%) smokers, $139(49.5 \%)$ obese (Table No.I). Duration of hypertension was greater than 20-25 years in most of the patients nearly $63.7 \%$ as shown in figure 1. Patients with long duration of diabetes and hypertension presented with intracerebral hemorrhage. Nearly all the patients with intracerebral hemorrhage were smokers 145 , only 2 patients were non smokers and nearly all had long history of smoking. There were 127 patients who presented with intracerebral hemorrhage were obese. All risk factors were statistically significant and were responsible for intracerebral hemorrhage.

\begin{tabular}{|l|c|}
\hline \multicolumn{1}{|c|}{ Variables } & $\begin{array}{c}\text { Frequency and } \\
\text { percentage }(\mathbf{n = 2 8 1 )}\end{array}$ \\
\hline Age mean $\pm \mathrm{SD}$ & $37.89 \pm 7.33$ \\
\hline Smoking & $154(54.8 \%)$ \\
\hline Obesity & $139(49.5 \%)$ \\
\hline Intracerebral hemorrhage & $147(52.3 \%)$ \\
\hline DM & $158(56.2 \%)$ \\
\hline \multicolumn{2}{|c|}{ Table-I. Demographic \& clinical variables } \\
\hline
\end{tabular}




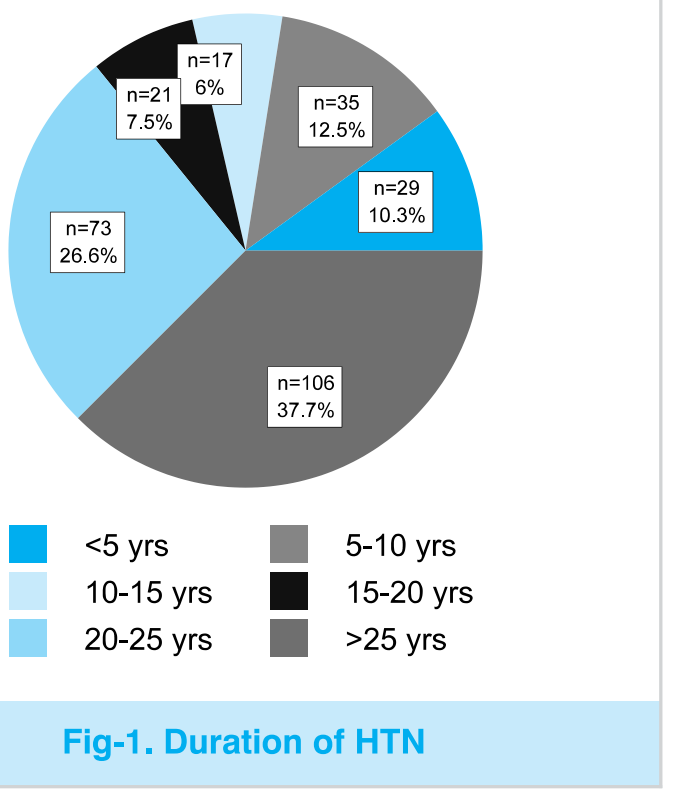

\section{DISCUSSION}

Stroke is the third most common cause of death and leading cause of disability in developing and developed countries ${ }^{11}$. WHO estimates nearly $20 \%$ of deaths in South Asia ${ }^{12}$. As no large scale, community based epidemiological studies are available in Pakistan, but annual incidence is nearly $250 / 100,000^{13}$. The highest prevalence reported in Pakistan was in adult Pushtoon community in Karachi i-e; $4.8 \%^{14}$, which is the highest ever reported prevalence in the world. Ischemic strokes being more common than hemorrhagic strokes, but the rate of hemorrhagic stroke is higher compared to Western population $^{15}$.

In our study the frequency of intracerebral hemorrhage seen in hypertensives were 52.3\% which was most commonly seen among males. This ratio was consistent with previous studies on gender $^{16}$, as rate in men has been declined from $2.8 \%$ in 2006 to $2.5 \%$ in 2009 , and then increased to $2.7 \%$ in $2010^{17}$. In our study three quarters of all the patients presented with intracerebral hemorrhage were under 50 years of age and the remaining one fourth were less than 65 years. However, Khan JA et al reported $26 \%$ of patients in 15-45 years of $\mathrm{age}^{18}$. Syed et al reported a frequency of $28 \%$ of young stroke under age of 55 years $^{19}$. Strokes can occur at any age but risk doubles each decade after age of 55 according to American Heart Association ${ }^{20}$. Vohra et al also reported $34 \%$ of patients fewer than 55 years of age $^{10}$. Among Americans age 65 and older prevalence is 40/ 1000 persons and one in 10 Americans over 75 has experienced stroke ${ }^{21}$.

The major vascular risk factors like hypertension, diabetes mellitus, smoking, dyslipidaemia and obesity is enormous in Pakistan. In our study, hypertension was the risk factor for the intracerebral hemorrhage. Longer the duration of hypertension, more was the incidence of the stroke. Hypertension is the leading cause of stroke especially intracerebral hemorrhage, but this rate is declining in developed countries largely due to efforts to control blood pressure and smoking. In Pakistan, a cross sectional survey conducted in tertiary care hospital revealed $39 \%$ of the people who had hypertension, dyslipidaemia and history of active smoking were in age range of 18-55 $\mathrm{yrs}^{22}$. Only $40 \%$ of hypertensive patients had controlled blood pressure ${ }^{22}$. It is also more prevalent in Southeastern region of the United States. The Framingham Heart Study showed the declining response of stroke over past 50 years, but lifetime risk is declining at a slower rate.

Other common risk factor is diabetes, which in our study was present in $56.2 \%$ of cases. Usually the patient which presented with stroke were of male gender with duration of diabetes was 5-10 years in most of cases. However previous studies showed $27-42 \%$ cases with diabetes ${ }^{18,20}$. Study in $2004^{22}$, in tertiary care hospital showed a much less incidence of diabetes among patients with stroke ie; $15 \%$. Same study showed incidence of obesity $24 \%$ of cases. In our study, there were $26 \%$ of cases who were obese according to $\mathrm{WHO}$ criteria.

While the other modifiable risk factor like smoking was found in half of the cases i-e; $54.8 \%$ and showed statistically significant correlation with intracerebral hemorrhage. Study of 100 patients conducted in $2008^{23}$, smoking reported to account for $94.7 \%$ of cases of stroke both hemorrhagic and ischemic stroke. While another study on risk factors of stroke showed $43 \%$ of smokers ${ }^{24}$. Our 
study was consistent with the findings of the previous studies; therefore the efforts should be made to reduce these modifiable risk factors in order to overcome this disabling disease.

\section{CONCLUSIONS}

Hypertension is an important risk factor for intracerebral hemorrhage. An effort should be placed to control blood pressure and other modifiable risk factors to reduce incidence of intracerebral hemorrhage and improve patient outcomes.

Copyright(C) 18 Nov, 2013.

\section{REFERENCES}

1. Moheet AM, Katzan I. Stroke, Disease management project 2010. [online] available from:url:http:///www:/synopsis/synopsis\%20refera nces/Stroke.htm.

2. Fischbein NJ, Wijman CA. Nontraumatic intracranial hemorrhage. NeuroimagingClin N Am. 2010 Nov;20(4):469-92.

3. Taj F, Zahid R, Syed UE, Murtaza M, Ahmed S, Kamal AK. Risk factors of stroke in Pakistan: a dedicated stroke clinic experience. Can J Neurol Sci. 2010 Mar;37(2):252-7.

4. Qureshi DA, Mendelow AD, Hanley DF. Intracerebral Hemorrhage. J Lancet 2009;373(9675):1632-1644.

5. Flaherty ML, Woo D, Haverbusch M. Racialvariations in location and risk of intracerebralhemorrhage. Stroke 2005;36:934-7.

6. Jafar TH. Blood pressure, diabetes and increased dietary salt associated with stroke- results from a community-based study in Pakistan. J Hum Hypertens 2006;20:83-5.

7. Kleindorfer D, Broderick J, KhouryJ. The unchanging incidence and case-fatality of stroke in the 1990s: a population-based study. Stroke 2006;37:2473-8.

8. Liebeskind DS, Kulkarni R, Nassisi D, Jeffrey L. Hemorragic Stroke In Emergency Medicine. :http://emedicine.medscape.com/article/1916662overview\#showall.

9. Asefa G, Meseret S. CT and clinical correlation of stroke diagnosis, pattern and clinical outcome among stroke patients visting TikurAnbessa Hospital. Ethiop Med J.2010 Apr;48(2):117-22.
10. Michael J, Schneck MD, José Biller MD. Hemorrhagic Stroke in the Tropics. Semin Neurol. 2005;25(3):300-6.

11. Feigin VL. Stroke epidemiology in the developing world. Lancet 2005;365:2160-61.

12. World Health Organization (WHO). The Atlas of Heart Disease and Stroke. http://www.who.int/ cardiovascular_diseases/resources/atlas/en/.

13. Pakistan stroke society. Last accessed on April 5, 2008. http://www.pakstroke.com/.

14. Jafar TH. Blood pressure, diabetes and increased dietary salt associated with stroke- results from a community-based study in Pakistan. J Hum Hypertens 2006;20:83-85.

15. Qureshi FS, Bilal A, Khan RR, Khalid G. Stroke; frequencies of intra-cerebral bleed, cerebral infarction and sub-arachnoid haemorrhage. Professional Med J Oct - Dec 2007; 14(4):580-5.

16. Morbidity and mortality weekly report. Prevalence of Stroke - United States, 2006-2010. CD C May 25, 2012 / $61(20) ; 379-382$.

17. Khan JA, Shah MA. Young stroke : Clinical aspects. J Coll Physicians Surg Pak 2000;10:46166.

18. Syed NA, Khealani BA, Ali S, Hasan A, Akhtar N, Brohi $H$. Ischemic stroke subtypes in Pakistan: the Aga Khan University Stroke Data Bank. J Pak Med Assoc. 2003;53:584-88.

19. American Heart Association. 2001 Heart and Stroke Statistical Update. Dallas, Texas: American Heart Association, 2000.

20. Vohra EA, Ahmed WU, Ali M. Aetiology and prognostic factors of patients admitted for stroke. J Pak Med Assoc. 2000; 50: 234-36.

21. Adams PF, Hendershot GE, and Marano MA. Current estimates from the National Health Interview Survey, 1996. National Center for Health Statistics. Vital Health Statistics 10(200). 1999.

22. Iqbal SP, Dodani S, Qureshi R. Risk factors and behaviors for coronary artery disease (CAD) among ambulatory Pakistanis. J Pak Med Assoc 2004;54:261-66.

23. Almani SA, Shaikh M, Shaikh MA, Shaikh K, Rahopoto Q, Baloch GH. Stroke: frequency of risk factors in patients admitted at Liaquat University 
Hospital Hyderabad/Jamshoro. J Liaquat Uni Med Health Sci Oct - Dec 2008;7(3):151-6.
24. Salma N Khan, Ejaz Ahmed Vohra. Risk factors for stroke: A hospital based study. Pak J Med Sci Jan Mar 2007;23(1):17-22.

\section{PREVIOUS RELATED STUDY}

Asad Ali, Aftab Turabi, Ahmad Danyal. STROKE; THERAPEUTIC POTENTIALS (Review) Prof Med Jour 12(2) 114-117 Apr, May, Jun, 2005.

Fraz Saeed Qureshi..., Ahmed Bilal, Rizwan Rasool Khan, Ghazala Khalid. STROKE; FREQUENCIES OF INTRACEREBRAL BLEED, CEREBRAL INFARCTION AND SUB-ARACHNOID HAEMORRHAGE (Original) Prof Med Jour 14(04) 580585 Oct, Nov, Dec, 2007

Mozzam Ali Atif. ISCHAEMIC STROKE; ROLE OF CAROTID DOPPLER (Original) Prof Med Jour 14(3) 448-453 Jul, Aug, Sep, 2007.

Muhammad Aftab Akbar, Mona Munir Awan, Sued Aftab Haider, Ghulam Mohy-ud-Din Choudhry. STROKE; ELECTOCARDIOGRAPHIC CHANGES (Original) Prof Med Jour 15(1) 91 - 95 Jan, Feb, Mar, 2008.

Syed Hashim Raza, Ali Imran, Mohammad Usman Ghani, Shahid Irfan, Qazi Masroor Ali. STROKE IN HYPERTENSION PATIENTS (Original) Prof Med Jour 10(2) 125 - 131 Apr, May, Jun, 2003.

Shakeel-ur-Rehman ..., Khalid Amin, Aamir Shoukat, Zafar Alam, Muhammad Zakira. STROKE IN HYPERTENSIVE PATIENTS; A CT SCAN BASED 100 CASE STUDY (Original) Prof Med Jour 11(4) 374-379 Oct, Nov, Dec, 2004.

Umair Masood, Muhammad Ansar Maqsood, Anjum Anwar Qadri. STROKE; SEASONAL VARIATION IN ETIOLOGY (Original) Prof Med Jour 13(4) 680-686 Oct, Nov, Dec, 2006.

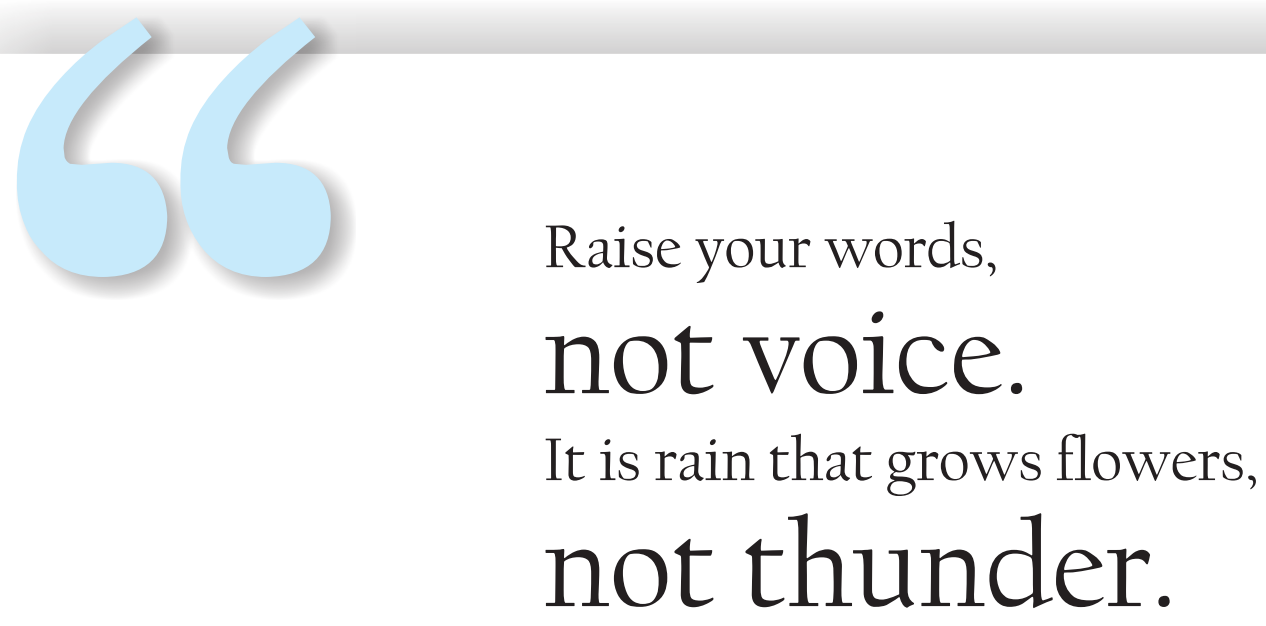

Hazrat Ali (R.A) 